\title{
Adaptive Morphing and Coping with Social Threat in Autism: An Autistic Perspective
}

\author{
Wenn B. Lawson*
}

Department of Educational Studies, Macquarie University, Sydney, Australia

\begin{abstract}
This paper highlights the role of terminology, such as camouflage and masking, commonly used in autism research. The author suggests researchers question assumptions around language commonly used to check it is fully representative of the autistic position. Being autistic often means being very literal. This literality means it is very important for researchers - particularly non-autistic researchers - to design research questions in a way that will gather accurate information often underlying autistic understanding. Words are powerful tools and lead to beliefs and positions held. Adaptive morphing in autism (currently referred to as camouflage or masking) infers a response, not of deceit, but one that is biological and not necessarily chosen. The author of this paper suggests masking, as a choice to deceive, is quite different from adaptive morphing for safety.
\end{abstract}

Keywords: Autism, masking, camouflage, language, adaptive morphing.

\section{INTRODUCTION}

As researchers, we often use questionnaires to aid in building a picture of participant responses and reasoning [1]. Such data helps our research to draw certain conclusions. The language one chooses in these questionnaires is exceptionally important because we want to represent participant culture and experience [2] fully. This paper aims to offer an opinion - to take a position - on terminology commonly used in current autism research related to camouflage. This terminology is being used to describe the actions of autistic individuals who, in trying to fit in with social situations, such as in families, schools, and workplaces, maybe obscuring their true selves [3]. The most popular terms currently used to explain this experience include masking and camouflaging. Masking appears to be used more commonly among the autistic community, while camouflaging is a term more often found in academic research [4, 5]. Both terms infer an intention and ability to deliberately and consciously 'pretend, deceive and cover-up', as a deliberate act. Of course, this may be a true statement for some. Here, though, I suggest that others on the autistic spectrum experience an overwhelming need to feel, and be safe, which guides behaviour and is not a 'choice' based upon pretence or deceit.

When we feel, or are, socially 'different', we viscerally and intuitively know that this increases the risk of group separation or exclusion (e.g., https://www.psychologytoday.com/us/blog/brainstorm/2 01607/we-all-want-fit-in (accessed September 5, 2020)

*Address correspondence to this author at the PO Box 5033, Warrnambool. Vic. 3280, Australia; Tel: +61 (0) 35562 7707; E-mail: wenbe2@outlook.com
This exposes us to increased social, emotional and physical risk and harm. So 'adaptive morphing' is a state that attempts to hide us from harm, enabling us to stay and feel safe. This emerges (especially in autism) not from an inherent or even conscious desire to deceive or pretend, but from a desire for survival.

Some autistic people have said that they were unaware that they were modifying their behaviour to try to fit in (Goodall, (2019) personal communication) [5]. Their awareness of this only became apparent once they had heard the terms camouflaging and masking. Some have also said they were not sure how they 'naturally' responded or behaved, as they had been prevented from doing so for most of their lives [5]. In this paper, the author addresses some issues concerning the language used in the current discourse about individuals on the autism spectrum and their efforts to appear socially appropriate.

For nearly two decades, literature [6-9] and personal blogs [10] have been referring to individuals on the autism spectrum (henceforth referred to as autistic individuals or autistics) as being able to camouflage, pretend, mask and blend in, in order to fit into social or other settings; to appear normal [9]. Cage and Troxell [11] demonstrate the negative impact such behaviour has on the mental health and wellbeing of those autistic adults by showing that their mental health was negatively impacted by camouflaging their autism. While I do not doubt the validity of this finding, I nevertheless question the terminology used. I am also concerned about the ways such terminology is being used in empirical studies, for example, being used as leading questions, and therefore closing down and narrowing participants' responses. 


\section{LANGUAGE}

Words are powerful, they shape - and are shaped by - our assumptions, perspectives and concepts [12]. As such, words can unintentionally lead others to certain beliefs or positions which may not be accurate or helpful. When positioning oneself with certain terminology or expressions, we need to consider the outcome. In using the powerful tool of language, it is our responsibility to make sure that the words truly represent an individual's or group's reality, are appropriate, and are not simply the language of the majority. For example, as stated above, when words such as pretend, mask, and camouflage are used, they imply intent to deceive; and deception implies conscious cheating.

\section{METHODOLOGY: AUTISTICS TALKING}

Following numerous conversations with multiple autistic individuals and over a hundred responses by autistic individuals to the 'Adaptive Morphing questionnaire' (see Appendix) about this subject of managing in social situations, the author has summarised some of the key recurring themes in the following quotations:

'...as autistic individuals, we are all different and neuro-diverse, but many of us are still wired for connection, the need for belonging and the need for a valued positive self-experience...' (Hall, personal communication 2019).

'So, as we grow up, we adapt ourselves to our environment and people, to achieve these desired states with as much ease and comfort as possible. I do not mind the effort of doing so, for this is far better than the consequences of not. Yet the effort it takes to be aware and adapt constantly can come at the cost of learning, earning, connecting and feeling rested and peaceful...' (Hall, personal communication 2019).

'From a very young age, when we do act intuitively, (i.e. spontaneously, and as we feel is appropriate in a given circumstance), we are swiftly informed either directly or through others' actions that what we've done is not ok. The human need to survive means that we have to learn to figure out what IS required in order to stay safe and not make ourselves a target. We do this both consciously and unconsciously across a lifetime but underpinning this response is the belief that our intuitive response is the WRONG way to act so we learn to distrust ourselves and our responses and begin to observe and mimic in a bid to blend in and pass unnoticed by those who might do us harm if they knew that we're different from the majority...' (Mahony, personal communication, 2019).

'As outsiders, we are teased, ridiculed, ignored, turned on. It seems our behaviour triggers others towards predatory actions, and this includes exclusion. This feels painful and scary. Loneliness holds as many health risks as poor lifestyle choices...' (Hall, personal communication 2019).

'Ultimately, masking for me, is liberating and debilitating in equal measure. I don't know how to take my masks off. I don't know how to live without masks. And they provide me with opportunities to be what I need to be for the people I love. But living a masked existence has robbed me of me. And I owe it to myself to try and find me. I owe it to the people I love to trust them enough to get to know me too even if I don't feel ready to 'Take My Masks Off' completely, yet' [5].

\section{WORDS, SOCIAL ATTITUDES AND POSITIONS}

Social attitudes have always influenced language and vice versa [13]. Taking a stand, holding a position on certain discourse and bringing to attention such a position, is important as it impacts not only attitudes but how research is conducted. The positions we take can also determine who gets to have a say, what types of power are used and what access to rights, obligations and duties an individual, or a group may exhibit. To this effect, Harré, (2012) [14] states:

'......based on the principle that not everyone involved in a social episode has equal access to rights and duties to perform particular kinds of meaningful actions at that moment and with those people... In many interesting cases, the 
rights and duties determine who can use a certain discourse mode...A cluster of short-term disputable rights, obligations and duties are called a "position". (p. 193).

Taking aside, making a judgement and/or holding a position about something, is not unusual, we all do this, individually and collectively. Sometimes, we take a position on something as part of our journey to uncovering what we really think or feel. Sometimes, as new understandings are being formed, we use words and terminology to help us make sense of what we think we are learning. In developing awareness and understanding, sometimes the pendulum of opinion swings fervently from one extreme to the other before it settles down. So, assisting the discourse by making sure we position ourselves in ways that liberate and contribute to an open discussion, is both helpful and an important part of good research practice. To make sense of what I intend may take time and effort. It is the author's hope that his position on current terminology will assist researchers to carefully consider how they word the questions in any research that explores coping strategies in autism. This is important because research is often used as a rationale for policy and practice, and subsequently influences how individuals and groups create and sustain assumptions, guidelines, expectations and conduct.

Slocum-Bradley (2010) [15] states, 'if I understand how I construct social reality, I can construct more consciously to sustain norms that promote the ends I profess to desire' (p. 81).

In 2020, person-first language (e.g., a person with autism) is increasingly being exchanged for identity-first language (e.g., autistic person). This has been driven by the autistic majority, concerned that phrases like a person with autism suggest that autism can somehow be separated from them, allowing the person (without autism) to be seen. Therefore, person-first language is viewed by many autistics as misleading and an inaccurate description of who they really are. The author of this paper is concerned that words used to describe some autistics' coping strategies are misleading too.

Therefore, concerning the terminology being used in research papers and in other literature on this topic, it is important to represent the broader autistic community. With this awareness, I note that some autistics may notice social intention and predict a socially acceptable response. However, most of us will have difficulties with this due to delayed object permanence [16], underdeveloped interoceptive connection [17] and be very much one-tracked or single-focused in our attention and experience [18]. Therefore, autistic ways of interacting socially are often observed to involve less small talk and social niceties, and more specific and focussed interactions involving topics of mutual interest. This behaviour is at odds with normative social expectations and can often lead to the strengths of this ability to focus and specialise being ignored or dismissed as too intense or too personal and not socially acceptable. Yet it is often these very traits that set us apart which can be our greatest strengths and enable us to be compassionate, empathetic, direct, focussed and productive, for example, see Greta Thunberg in: https://www.theguardian.com/environment/2019/sep/02 /greta-thunberg-responds-to-aspergers-critics-its-asuperpower (Accessed September 5, 2020).

\section{SURVIVAL}

People's responses to a perceived threat can be a fight, flight, freeze, flop, drop, fawn and possibly morph. Social exclusion can be a strong and visceral perceived or actual threat. The author believes that our human inbuilt survival mechanisms are prompts that trigger many autistics to seek and enact socially acceptable observed, rather than intuitive, thoughts and behaviours to stay safe. In this way, this marginalised group is finding a social solution to the social problem of being subjected to unspoken social rules and expectations which they experience as a culture of negative experiences and expectations from the dinner table, to the classroom, to the shop floor [19].

In a world where non-autistics are the majority, their social interaction style is considered the acceptable one. This norm is based on the functions of a brain wired to enable social connection in a manner appropriated by the utilisation of polytropic interests [20]. This is only possible because of its communication system, which allows for attention to multiple foci at once, which leads to a set of behaviours that are valued and rewarded by the neuro-majority. Some of these are considered as appropriate eye contact, appropriate facial expression, appropriate reading of body language, and connected interoceptive awareness [16, 17]. Autistic social behaviours and preferences which differ from societal norms are pathologised and called a disorder or condition, as they do not conform to these normative ascribed styles. 
People who are naturally able to conform to society's social expectations have no need to behave in a way contrary to their nature in order to be socially acceptable and rewarded. Many autistics 'choose' or 'act' in ways contrary to their natural behaviours to increase their chances of social inclusion and, thus, decrease their risk of negative consequences from the non-autistic majority.

Is this, however, deliberate deception or a survival strategy cultivated over many years? Is this a conscious act or a subconscious response to real and/or perceived trauma? Yes, many autistics cover up aspects of themselves they wish to keep hidden, as a response to trauma. According to the conversations concerned with this project, those who shared in this together said:

'... for me sometimes this is done subconsciously; rarely is it done deliberately. In fact, it's only as I talk together that I realise I have been doing this over many years....'. (Goodall, personal communication 2019).

And:

'... I don't think my intention is to deceive others into thinking I'm something I'm not it's more about trying to do what l've been told. Or, not do what my family have told me to contain' (Newgent, personal communication 2020).

Additionally, many autistics have under-developed interoception, and this keeps us from recognising many of our inner bodily senses such as hunger, thirst, pain, desire, temperature and heart rate, and can also interfere with the recognition of emotive states $[8,18$, 21]. If one has underdeveloped interoception, and a brain (and mind) that is designed for single-focused attention to one thing at any one time [20,22], then you might not naturally develop a global map of neurotypical social appreciation because you may have a brain disposition that naturally processes information differently, rather than the typical multi-tasking expected during daily life and socialising. You may also find it unnatural to look, listen, speak and walk all at the same time, preferring to focus upon single events and connections across a single interest [8, 18, 20, 22]. You might naturally be 'wired' with a different neural infrastructure to that of a neurotypical person. This means that you are biologically and intuitively drawn to focussing differently from how a non-autistic person might. Many autistics will focus on the things that matter to them rather than being and doing social unless social is an aspect of their interest [8]. Also, it is important to note that the human brain - whether autistic or Neurotypical - manages best when it can focus upon one thing at any one time [23].

As well as being seen as a socially-mediated skill, autistic coping and adaption could also be seen as biologically programmed and activated in order to keep oneself safe. It is suggested, we often observe others to see what it is that they do. As we practise these ways, we note what might work and what does not work. For example, for anticipatory or current social discomfort, some autistics may use demand-avoidant methods such as refusal to cooperate, pleading inability, or controlling a situation to enable a reduction in anxiety and increase comfort (See: https://www.autism.org.uk/advice-and-

guidance/topics/diagnosis/pda) accessed September 5, 2020). Alternatively, they may choose to interact in a defensive, competitive or combative way. Yet some may prefer to morph and adapt their behaviour to mimic non-autistic strategies that they have seen in attempts to create social connection, success, and reward from others. This morphing can be compared to tactics used by some chameleons.

\section{ADAPTIVE MORPHING}

Nature teaches us many things about ways to survive and one lizard particularly, begs our attention. It is the Chameleon. Chameleon is a term used to describe a certain type of highly specialised lizard. It is an Old World clade, meaning from a single source heritage, but with multiple presentations. A Chameleon, being an Old World lizard, has been around a very long time. So has autism [24] (see also https://www.parents.com/health/autism/the-history-ofautism/ accessed September 5 2020). There are many interesting things about chameleons, one being that some can change their colour to match their surroundings and circumstances, as well as males choosing to enrich their colour choices as a biological method for attracting mates. However, this is not a chosen activity so much as a means built into their biology, which is usually triggered by environmental temperature, perceived threat or the need to mate [25].

When we compare the chameleon's threat/mate response to autistic morphing, the author believes we are closer to understanding the strategies some 
autistics use to help them navigate social situations and expectations. Because of the intrinsically human desire to belong, many autistics are drawn by both biology and necessity to be included with and accepted by, the non-autistic majority $[8,18]$. However, without true inclusive adjustments that allow for genuine inclusion and acceptance, this desire will continue to be thwarted by the stigma that is still associated with autism. As long as our society lacks truly inclusive attitudes and practices, autistics will need to continue to display chameleon-like responses in socially threatening situations. Our mental, emotional, physical and financial lives depend on it $[4,5,9,26]$.

\section{FEMALE AUTISTICS}

In recent publications, including by the author [27], the words masking and camouflaging are used to explain why females on the spectrum have remained invisible, and do not figure in either historical or recent statistics. Initially, it was reasoned that they failed to show in the data because autism was predominantly a male condition [28]. In later years it was argued females were more immune to autism because of the properties of oestrogen, which gave them certain protection against becoming autistic [29, 30]. More recently, females are said to use masking and camouflage to hide their difficulties $[4,5,8,9,10]$.

Biologically, due to inherent attributes on the $X X$ chromosome, autistic females, and females in general, tend to be more social [30]. This could mean Females are able to notice and use more acceptable social behaviours because certain behaviours appear to be more available to them than they are to those without the XX chromosome [31]. This suggests that, from a young age, autistic girls may have noticed others and learnt how to act as if they understood normative and expected social motivation, dynamics and behaviours, even when they did not intrinsically know these. Therefore, their actions act as a mask that covers their real difficulties. However, in this scenario, masking as camouflage may not be a chosen state or a conscious act. Rather, it is the result of enacted behaviour to avoid the discomfort of not fitting in or fear of being punished or shunned and may have happened almost automatically, without conscious awareness, planning, or control $[32,33]$. Of course, recourse to this behaviour is not only unique to females!

As well as avoiding discomfort in social situations by adapting behaviour, autistics can appear to have a level of social ability that adheres to normative expectations. This may then reduce the level of discomfort that others have with them. Additionally, for female autistics, specific passionate interests exist that are more commonly accepted as typical in any female. These could be a passion for books, animals, people, art, fashion, theatre or music. As these pursuits are often appreciated and rewarded by society for females, they may not be recognised as being particularly single-focused or rigid. As a result, their autistic characteristics may pass unnoticed [31-33].

Due to the above scenario, autistic females may also have more internalising psychological characteristics than autistic males, such as anxiety or depression. They may also have more self-directed symptoms like self-blame and low self-worth, and fewer externalising behaviours such as aggression or challenging behaviours that are more typical of autistic males $[4,5,8,9,26,29,31-33]$. Such variable and critical difficulties may commonly go unnoticed by parents or teachers. Unfortunately, though, in the longterm, these behaviours and strategies which lead to females remaining unidentified as autistic, can often lead to their mental health being negatively impacted. As a result, females are more often misdiagnosed with other issues such as depression, personality disorders, social phobia, eating disorders and anxiety disorders, than are autistic males [27, 31, 32]. They are also much more likely to have these as comorbidities [27]. This could mean the psychological issues may be noticed and treated, but the underlying autistic cause may not be addressed, compromising the ability to create sustainable and positive mental health and identity outcomes.

Therefore, due to these worrying trends that concern the author of this paper, it is the authors' position that using terms such as masking and camouflaging could be thought of as misleading terms. For example, when it comes to such words being used as terms for explaining and naming certain individuals' experiences, these should be used to explain the positive unintended outcome of specific learnings, not the chosen activity.

So, if we think of autistics using a mask to camouflage their difficulties, we are suggesting they are using deceit and dishonesty. This is not the intention, but it appears as a natural conclusion. However, where autism is concerned, if we say that camouflage is achieved through activities that unwittingly cover up areas of difficulty, we are saying something different and something more accurate. This 
is not chosen deception, so much as a biological response to a perceived threat. Therefore, for example, in research questionnaires, I cannot help but wonder if an outcome of a question that asks:

'... do you remember when you first began to use camouflage to mask your difficulties?'

...would be different from a question that asks:

'do you think you observed the need to be socially hidden and safe and found ways to achieve this?'

Camouflage would be the result in both situations, but one demonstrates the intention to deceive; the other shows a learnt or intuitive outcome to maintain safety. Maybe we need to avoid words like masking, pretending and hiding; perhaps adaptive morphing, like that triggered by threat/need in the chameleon biology, more accurately encapsulates what is happening? This also removes the negative and pejorative connotations of the alternative descriptors which have been used until now.
It remains the author's hope that all research concerning aspects of camouflage and autism will be explored via the lens explained above. One day, autism will be recognised for the norm that it is, for many individuals. It will, therefore, be the norm to see individuals wearing sunglasses and/or tinted lenses and/or a baseball cap when inside; the norm to use a weighted garment or soft toy to aid relaxation; the norm for individuals to choose not to be social unless sharing a mutual interest, and the norm to be themselves without the need to hide who they truly are.

\section{ACKNOWLEDGEMENTS}

The author acknowledges Joanne Mahony and Gabrielle Hall, who added their thoughts and comments to this work. Thanks also go to Professor Liz Pellicano and all the autistic adults who so willingly shared their experiences with me. The author also acknowledges The Cooperative Research Centre for Living with Autism (Autism CRC), established and supported under the Australian Government's Cooperative Research Centres Program. However, The Autism CRC was not involved in the project and/or writing of this paper.

\section{APPENDIX}

\section{Adaptive Morphing Questionnaire}

Please circle the answer(s) that best suits you.

1. In social gatherings with unfamiliar others I behave in ways I perceive as 'expected' to stay:

$$
\text { safe hidden noticed accepted }
$$

2. In social gatherings with other autistics I behave in ways I perceive as 'expected' to stay:

$$
\text { safe hidden noticed accepted }
$$

3. In social gatherings with family I behave in ways I perceive as 'expected' to stay:

$$
\text { safe hidden noticed accepted }
$$

4. In social gatherings at work I behave in ways I perceive as 'expected' to stay:

$$
\text { safe hidden noticed accepted }
$$

5. In social gatherings with non-autistic friends I behave in ways I perceive as 'expected' to stay:

$$
\text { safe hidden noticed accepted }
$$

6. In my own home, I behave in ways I perceive as 'expected' to stay:

$$
\text { safe hidden noticed accepted }
$$

7. When outside of the home, I behave in ways I perceive as 'expected' to stay:

$$
\text { safe hidden noticed accepted }
$$


8. In which of the above scenarios is your behaviour consciously chosen? Questions:

$$
\begin{array}{llllllll}
\text { None } & 1 & 2 & 3 & 4 & 5 & 6 & 7
\end{array}
$$

9. Do you consider your responses in various social situations to be based upon what is natural and usual for you, or does it depend upon the need to feel:

safe hidden noticed accepted

10. Would you describe your 'social' behaviour in general to reflect a need to be:

safe hidden noticed accepted

Thank you for taking part in this study.

Dr. Wenn B. Lawson (PhD) CPsychol

wenbe2@outlook.com

\section{REFERENCES}

[1] Allery LA. Design and use questionnaires for research in medical education. Education for Primary Care 2016; 27(3): 234-238. https://doi.org/10.1080/14739879.2016.1175914

[2] McGrath C, Palmgren PJ, Liljedahl M. Twelve tips for conducting qualitative research interviews. Medical Teacher 2019; 41(9): 1002-1006.

https://doi.org/10.1080/0142159X.2018.1497149

[3] Hull L, Petrides KV, Allison C, Smith P, Baron-Cohen S, Lai MC, Mandy W. "Putting on My Best Normal": Social Camouflaging in Adults with Autism Spectrum Conditions. Journal of Autism and Developmental Disorders 2017; 47(8): 2519-2534.

https://doi.org/10.1007/s10803-017-3166-5

[4] Lai MC, Lombardo MV, Ruigrok AN, et al. Quantifying and exploring camouflaging in men and women with autism. Autism 2017; 21(6): 690-702. https://doi.org/10.1177/1362361316671012

[5] Heyworth M. Take The Mask Off (but what if I don't know how?) - Reframing Autism Blog August 26, 2018. https://www.reframingautism.com.au/takethemaskoff/

[6] Attwood T. The Complete Guide to Asperger's Syndrome. London: Jessica Kingsley Publishers 2007.

[7] Howlin P, Moss P. Adults with autism spectrum disorders. Canadian Journal of Psychiatry 2012; 57(5): 275-283. https://doi.org/10.1177/070674371205700502

[8] Livingston LA, Shah P, Happe F. Compensatory strategies below the behavioural surface in autism: a qualitative study. The Lancet, Psychiatry 2019; 6(9): 766-777. https://doi.org/10.1016/S2215-0366(19)30224-X

[9] Holiday-Willey LH. Pretending to be Normal: Living with Asperger's Syndrome. London: Jessica Kingsley Publishers 1999.

[10] Nirode V. 'Why I Fake Being 'Normal' - and Other Women with Autism Do, Too' July 11, 2018. https://www.healthline. com/health/autism/how-women-camouflage-autism\#1

[11] Cage E. Troxell-Whitman Z. The reasons, contexts and costs of camouflaging for autistic adults. Journal of Autism and Developmental Disorders 2019; 49(10). https://doi.org/10.1007/s10803-018-03878-x

[12] Bowman C, Ronch J. Madjaroff G. The Power of Language to Create Culture. Rotheschild Foundation US 2012.
[13] Preston D. The power of language regard: Discrimination, classification, comprehension and production. Dialectologia 2011; (Special issue) 2: 9-33.

[14] Harré R. Positioning theory: moral dimensions of socialcultural psychology. In J. Valsiner (ed.) The Oxford Handbook of Culture and Psychology. New York: Oxford University 2012; pp. 191-206. https://doi.org/10.1093/oxfordhb/9780195396430.013.0010

[15] Slocum-Bradley N. The positioning diamond: A transdisciplinary framework for discourse analysis. Journal for the Theory of Social Behaviour 2010; 40(1): 79-107. https://doi.org/10.1111/j.1468-5914.2009.00418.x

[16] Lawson W, Dombroski B. Problems with Object Permanence: Rethinking Traditional Beliefs Associated with Poor Theory of Mind in Autism. Journal of Intellectual Disability - Diagnosis and Treatment 2017; 5: 1-6.

https://doi.org/10.6000/2292-2598.2017.05.01.1

[17] Goodall E. South Australian Government Dept. for Ed. Disability, Policy \& Programs 2019: https://www.education. sa.gov.au/sites/default/files/understanding-the-autismspectrum.pdf?acsf_files_redirect

[18] Lawson W. The passionate mind: JKP: London 2011.

[19] Wood R. Autism, intense interests and support in school: from wasted efforts to shared understandings, Educational Review 2019. https://doi.org/10.1080/00131911.2019.1566213

[20] Murray DK, Lesser M, Lawson W. Attention, monotropism \& the diagnostic criteria for autism. The International Journal for Autism: Sage 2005.

\section{https://doi.org/10.1177/1362361305051398}

[21] Lawson W. Object Permanence, Interoception and Theory of Mind Supporting Document. Department of Education, Government of South Australia 2018. https://www.education. sa.gov.au/sites/default/files/object-permanenceinteroception-and-theory-of-mind-supporting-document.pdf)

[22] MuËller RA. Anatomical and Functional Connectivity in Autism Spectrum Disorders. In: Patel VB, Preedy VR, Martin $\mathrm{CR}$, editors. Comprehensive Guide to Autism. Springer New York 2014; pp. 49-75. https://doi.org/10.1007/978-1-4614-4788-7 192

[23] Gopher D, Armony L, Greenspan Y. Switching tasks and attention policies. Journal of Experimental Psychology: General 2000; 129: 308-229.

https://doi.org/10.1037/0096-3445.129.3.308 
[24] Feinstein A. A history of autism: Conversations with the pioneers. Wiley UK 2010. https://doi.org/10.1002/9781444325461

[25] National Geographic. The Colorful Language of Chameleons 2015.

[26] Baldwin S, Costley D, Warren A. I Belong: The experiences, aspirations and needs of adults with Asperger's disorder and high functioning autism. Autism Spectrum Australia (Aspect) 2013.

[27] Lawson W. Women and girls with autism: a profile. Journal of Intellectual Disability - Diagnosis and Treatment, 2017; 5: 9095.

https://doi.org/10.6000/2292-2598.2017.05.03.4

[28] Constantino John N, et al. Gender bias, female resilience, and the sex ratio in autism. J American Acad. of Child \& Adol Psych 2012; 51(8): 756-758. https://doi.org/10.1016/j.jaac.2012.05.017

[29] Head AM, McGillivray JA Stokes MA. Gender differences in emotionality and sociability in children with autism spectrum disorders. Molecular Autism 2014; 5: 19.

https://doi.org/10.1186/2040-2392-5-19
[30] Cox KH, Quinnies KM, Eschendroeder A, Didrick PM, Eugster EA, Rissman EF. Number of X-chromosome genes influences social behavior and vasopressin gene expression in mice. Psychoneuroendocrinology 2015; 51: 271-281. https://doi.org/10.1016/j.psyneuen.2014.10.010

[31] Carpenter B. Happe F, Egerton J. Girls and Autism: Educational, Family and Personal Perspectives. Taylor \& Frances UK 2019. https://doi.org/10.4324/9781351234429

[32] Eaton J. A Guide to Mental Health Issues in Girls and Young Women on the Autism Spectrum: Diagnosis, Intervention and Family Support. JKP: LondonLawson, W. (1998) Life behind glass. Southern Cross University Press. NSW 2017.

[33] National Autistic Society, City Rd. London. https://www.autism.org.uk/about.aspx

DOI: https://doi.org/10.6000/2292-2598.2020.08.03.29

(C) 2020 Wenn B. Lawson; Licensee Lifescience Global.

This is an open access article licensed under the terms of the Creative Commons Attribution Non-Commercial License (http://creativecommons.org/licenses/by-nc/3.0/) which permits unrestricted, non-commercial use, distribution and reproduction in any medium, provided the work is properly cited. 